\title{
Tribes of Odisha: Issues of social inclusion, exclusion and cultural assimilation
}

- Dr. Tanuja Mohapatra

Culture and society are dynamic. Culture and society change over time due to several factors - exposure, invention, experimentation and change in the surrounding environment. The tribal societies in India are also no exception.

In India, there is an amalgam of 437 tribes, and in Odisha the number is 62. According to the 2011 Census, in Odisha the total strength of tribal population is approximately nine million, which constitutes $22.19 \%$ of the total population of the State (total population of Odisha is estimated to be 41,947,358).

In common parlance, tribes in India are perceived as 'different' socio-cultural groups living in isolation since the mythical Aryan invasion of the Indian sub-continent. It has been hypothesized by many that the tribes were pushed by the invaders - the 'pure' races - with superior military strength into the interior hilly and forest abodes and since then the tribes have been leading a life of seclusion. Social exclusion issues in India are gaining more relevance by the day. This is primarily because while India as a country is growing at a decent growth rate, not all sections of society have been able to take advantage of this growth. A large majority of people are yet to enjoy the benefits of this development and still remain excluded. Social exclusion has got at its centre the idea that some individuals are outside the society in one way or the other.

There is lot of controversy over the present day development paradigm of tribal development. The tribal people have been facing problems from both inclusion in to and exclusion from the dominant development paradigm of the country. The tribal 
societies have experienced religious and other cultural inclusion in to the so called universal or dominant culture and consequently faced the problem of identity crisis. Exclusion from infrastructure and health and education etc has led them to a situation where they find it difficult to cope with the outside world at present day situation.

The present highlights the characteristics of inclusion and exclusion of tribal societies in Indian situation.

\section{Inclusion and exclusion}

The paper tries to find out what are the means and aims of exclusion and inclusion, and the consequences of the same with some instances on the tribes of Odisha.

The term 'social exclusion' and 'social inclusion' are two terms most widely used in recent years by politicians, social scientists and the public as well. The term social inclusion was originated in French social policy in the 1970s. It came into play in the 1980s economic crisis (Benn, 2000) when state sponsored republican tradition of solidarity was in vogue (Bhalla and Lapeyre, 1997). By the year 1990 the term was theorized by scholars like Bourdieu and Luhmann. The latter clarified the concept in the following terms:

The concept of inclusion means the encompassing of the entire population in the performances of the individual function systems. On the one hand, this concerns access to these benefits and, on the other, dependence of individual modes of living on them. To the extent that inclusion is achieved, groups disappear that do not or only marginally participate in social living (Luhman, 1990).

The definition of 'Social exclusion' was offered by the European Foundation that suggests representing the other end of the spectrum to 'full participation': "Social exclusion is the process through which individuals or groups are wholly or 
partially excluded from full participation in the society in which they live."

In the international arena, the United Nations Development Programme has been at the forefront of attempts to conceptualize social exclusion across the developed and developing world. A series of country studies led to the formulation of a rights-focused approach, which regards social exclusion as lack of access to the institutions of civil society (legal and political systems), and to the basic levels of education, health, and financial well-being necessary to make access to those institutions a reality.

Social exclusion refers to lack of participation in society and emphasizes the multi-dimensional, multi-layered, and dynamic nature of the problem. Definitions of the concept emanate from diverse ideological perspectives, but most share the following features:

- Lack of participation. Protagonists differ over which aspects of society are important and where responsibility for non-participation resides. Most agree that exclusion is a matter of degree, since individuals may be participating to a greater or lesser extent, and that it is relative to the society in question.

- Multi-dimensional. Social exclusion embraces incomepoverty but is broader: other kinds of disadvantage which may or may not be connected to low income, such as unemployment and poor self-esteem, fall within its compass.

- Dynamic. The advent of dynamic analysis and a demand from policy makers to investigate cause as well as effect has generated an interest in the processes which lead to exclusion and routes back into mainstream society.

- Multi-layered. Although it is individuals who suffer exclusion, the causes are recognized as operating at 
many levels: individual, household, community, and institutional.

Thus, in totality, social exclusion denotes the following characteristics of a society at large or individuals at least.

i) Inability to participate effectively in economic, social, political and cultural life.

ii) Distance and alienation from a so called mainstream society.

iii) Isolation from major societal mechanisms which produce or distribute social resources.

Social exclusion is a broader concept. It is a related concept with unemployment and poverty, but not an identical one with them. Social exclusion is a relative term particular to a place or country on certain circumstances. It is always related to a social agent or agents. Exclusion is also dynamic term depending upon people's immediate condition. Social inclusion and social exclusion can also be viewed in terms of market economy. In this sphere the phrase social exclusion is used to describe a situation as also to focus on a process, which excludes individuals or groups from livelihoods and rights, thus depriving them of sources of sell-being that have been assumed, if not taken for granted, in industrial countries.

On the contrary, the literature of developing countries has sought to study marginalization or deprivation of majorities through a focus on poverty and inequality. Market base proposition says that it may exclude people as consumers or producers or both. Market excludes people as consumers or buyers if they do not have any income, or sufficient income, which can be translated into purchasing power. Markets exclude people as producers or sellers if they have neither assets nor capabilities. In addition, market excludes both as consumers and producers and as buyers and sellers if they do not accept, or conform to, the value of a market system. The 
most obvious example of such exclusion is tribal population or forest communities in a market economy.

\section{Impact of inclusion and exclusion}

Though it is generally presumed that exclusion is detrimental and inclusion is for good, in practice this may not be true. Coercive inclusion by market or by dominant social system in any form may cause harm to the social web of the new entity. Coercive inclusion may be in the form of child labour, women in wage labour with differential payments, putting tribal people in unskilled and unprotected labour force and as immigrant workers etc. For similar reason, exclusion is not always bad. To those who do not accept the value of the market system and do not resemble or depend on a social system outside their traditional domain, any voluntary exclusion from those entities should be perfectly accepted. Both from social and market perspective discourse on inclusion and exclusion of tribal people cater relevance in present situation. Because, it is said that exclusion and poverty are mostly interrelated. Conventional poverty indicators reveal that there is a strong correlation between being indigenous or tribal and being poor or extremely poor. Tribal people are more likely to have lower income, poorer physical living conditions, less access to health care, education, and a range of other services, worse access to labour, land and capital markets and worse returns to work as well as weaker political representation. The poverty and social exclusion experienced by tribal people are largely due to discrimination at social and institutional level during colonial and post independent era.

\section{Tribes of Odisha and the tribal society}

On the basis of certain specific characteristics some human societies are defined as tribal societies across the world. These characteristics are not uniform for every society. But there are certain characters universal to all of them; at least they had derived from such a social arrangement at certain point of time. 
According to the ILO Convention No. 169 indigenous and tribal peoples are those peoples "whose social, cultural and economic conditions distinguish them from other sections of the national community, and whose status is regulated wholly or partially by their own customs or traditions or by special laws or regulations".

In India there is an amalgam of 437 tribes, and in Odisha the number is sixty. According to 1991 Census, in Odisha the total strength of tribal population is approximately seven million which constitutes $22.21 \%$ of the total population of the State. Linguistically the tribes of India are broadly classified into four categories, namely (1) Indo-Aryan speakers, (2) Dravidian speakers, (3) Tibeto-Burmese speakers, and (4) Austric speakers. In Odisha the speakers of the Tibeto-Burmese language family are absent, and therefore Odishan tribes belong to other three language families. The Indo-Aryan language family in Odisha includes Dhelki-Oriya, Matia, Haleba, Jharia, Saunti, Laria and Oriya (spoken by Bathudi and the acculturated sections of Bhuyans, Juang, Kondh, Savara, Raj Gond etc.). The Austric language family includes eighteen tribal languages namely, Birija, Parenga, Kisan, Bhumiji, Koda, Mahili Bhumiji, Mirdha-Kharia, Ollar Gadaba, Juang, Bondo, Didayee, Karmali, Kharia, Munda, Ho, Mundari and Savara. And within the Dravidian language family there are nine languages in Odisha, namely, Pengo, Gondi, Kisan, Konda, Koya. Parji, Kui, Kuvi and Kurukh or Oraon.

The tribes of Odisha though belong to three linguistic divisions, yet have lots of socio-cultural similarities among them. These commonalities signify homogeneity of their cultures and together they characterise the notion or concept of tribalism. Tribal societies share certain common characteristics and by these they are distinguished from complex or advanced societies. In India tribal societies had apparently been outside the main historical current of the development of Indian civilization for centuries. Hence tribal societies manifest such 
cultural features which signify a primitive level in sociocultural parameter.

\section{Process of tribal absorption in Odisha}

The tribal-nontribal interface is perhaps more glaring in the case of Odisha, where the culture is better construed as an amalgamation of tribal and sanskritic elements, represented in its religious beliefs and practices, rituals, myths and folklores, the emotions and everyday behaviour of the Odias. The state of Odisha has been a land of adivasis, literally the original inhabitants of the land, and known as tribes in common parlance. According to the latest Census, the tribal population constitutes $22.2 \%$ of the state population and divided into 62 groups with their distinct cultures, customs and languages. The culture, heritage and folk life of Odisha, identified with the cult of Jagannath, is believed to have originated from the pantheon of the Savara - one of the adivasi communities inhabiting this part of the country for millennia. Mention has been made in the Utkala khanda of the Skanda Purana that the legendary king Indradumna, ruling from a city called Avanti in the Kingdom of Malwa was a great devout of Lord Vishnu, who deputed his close confidant, Vidyapati, to meet the Savara king Viswabasu and bring back the idol of Lord Jagannath, believed to have been worshipped in absolute secrecy as Nilamadhava by the Savara. The legend goes that Vidyapati had to marry the daughter of the Savara king, Lalita, in order to locate the idol. Eventually, king Indradumna had to visit Odisha on divine instruction to collect the piece of wood for the fabrication of the idol of Lord Jagannath (Das 2005). Despite many different legends on the origin of the cult which do not have any credible historical evidence either to accept or reject, "it is clear that the present form of the Lords bear resemblance to tribal art. Hence, the tribal origin of Jagannath cannot be ruled out" (Dash, 2005).

With this social, spiritual and historical background of Odisha, what is contended here is that tribes and castes were and are not mutually exclusive cultural categories in Odisha and other 
states of India, although this division could, at best, culminate in analytical categories for academic purposes. In other words, mobility between castes, popularized as Sanskritization by Srinivas (1972), has been complemented with an additional process of tribe-caste mobility, placing both the categories on a continuum. This essay aims at exploring this continuous process of mobility in the state of Odisha with ethnographic evidences indicating how some tribes have acquired the caste status and some castes have acquired most of the tribal cultural features being encysted in tribal dominated regions of the state.

It is established from many historical records that during the mediaeval times the process of tribe-caste integration and particularly, status mobility of tribes to castes, was mostly patronized by the temple administrations, the local kings or feudal chiefs or influential zamindars, thus institutionalizing the achieved higher status of specific tribes (Mahapatra, 1976). This, however, does not undermine the usual process of tribal cultural assimilation with the castes, even without patronage, as a part of prolonged association and influence by the neighbouring populous caste groups. What is still more amazing is the process of assimilation of the caste communities into the tribal cultures, when the former remain encysted for long in a tribal dominated region.

Another major agent of tribal absorption was the Christian religion. Christianity and Tribal people are closely related in certain tribal pockets in India, so also in Odisha. Christianity entered India as a charity, working in disadvantaged localities, mostly following the colonial rule. Unlike Hindu method of tribal absorption, Christianity took a different route. Generally, it associated religion with humanity and sufferings, education and liberal views. Definitely, the incentives or the driving force was not religion and the legendry links to a greater world outside tribal domain. It was the basic requirements for survival - health, education and economic betterment etc. 


\section{Odisha: Land of castes and tribes}

The geo-physical character of the state of Odisha with its natural landscape overshadowed by high mountains, deep forests and difficult terrains with an extensive chain of river systems, was perhaps most inaccessible in ancient times, but might have been an excellent abode for the refugees (Bose, 1967). The difficult land route and dangerous river passes might have provided a safe and unmolested habitation for those indigenous communities, who were pushed back to the interior and hilly regions by the invading population from the northwest. This refugee population, in all probability, might have been the indigenous population or the autochthones of the land, and hence, the culture of Odisha has a strong tribal base. But the later waves of migration must have brought in small groups of 'Aryan' communities, who might be completely encysted by the indigenous communities and influenced by their culture. Bose aptly observes:

Of the many aboriginal tribes who inhabited Odisha in early times, the foremost were the Savara. They have been in contact with people speaking Indo-Aryan languages for a very long time, and they have had some share in building up Odishan civilization. Scholars who study the history of languages say that the language of Odisha owes something to the Savara (ibid.).

Besides the Savara influence on the language, in the sphere of religion also the Savara have a significant place. The principal deity of Hindu Odisha, Lord Jagannath, is said to be of Savara origin and the Odishan myths and oral traditions are enriched by the stories of sincere endeavour and devotion of the kings and nobles in ordaining the status of the principal deity to this tribal shrine. Even today a section of the servicing population (sevayata) of the deity, namely 'Daitas', has a claimed tribal origin, which has been established and endorsed in many scholarly writings. 
Due to the predominance of caste population and the spread of world religions during the mediaeval and early-modern periods of Odishan history, the reverse trend gained prominence with the tribes emulating cultures and customs of the neighbouring caste groups with a view to assimilate with the latter. This process of cultural assimilation has been widely noticed among many agriculturist tribal populations of the state, as this occupation has been made open for a variety of castes and communities, unlike many other occupations having a strong caste reference and affiliation (viz. barbers, washermen, potters, smiths, carpenters, sweet makers, gardeners, and so on). There are, however, other elements of culture as well, which are also adopted in different degrees, facilitated by the stretch of positional proximity between the tribes and castes of Odisha and their long historical linkages. Advanced tribes and lower castes in Odisha tried to emulate the style of life of the castes that ranked higher than theirs in the local social order to attain higher social status and thereby prepare the ground for modernization. As suggested by Srinivas (1972), it is a social axiom that a group or a community adopts the life style of the economically, politically and numerically dominant group readily available locally as a reference group to ensuring upward status mobility among the tribes and relatively lower caste groups.

\section{Cultural assimilation}

The process of cultural assimilation and mobility along the tribe-caste continuum in Odisha is bi-directional with mutual emulation of culture traits and the way of life. But the formal and institutionalized integration is only confined to the tribes being given the caste status and declared as touchables. Similarly, although the tribal-encysted castes mostly adopt tribal customs and cultures in their everyday life, there is hardly any tangible evidence in Odisha to prove the deviation of the rule of endogamy with respect to these castes. 
Bose's contemplation on the cultural absorption of the Juang (one of the Primitive Tribal Groups or the PTGs living in Keonjhar and the neighbouring districts) of Odisha with the proximal Hindu communities may be taken as a glaring example and the outcome of a pioneering research in Odisha. The Juang, inhabiting the rugged terrain and dense forested area of Keonjhar were not observed to be so close to caste culture, as had happened in case of a section of the tribe migrated to the plains of the neighbouring Dhenkanal district. They were mostly basket makers with wet agriculture supplementing their livelihood. Bose has delineated in very clear terms the adoption of Goddess Lakshmi as their deity and Her propitiation along with frequent use of terms like satya, devata, dharma, etc. in their religious and magical lore. These evidences have made Bose to infer the subtle operation of the process of Hinduization among them (Bose, 1967). It is evident from these observations that although the plains living Juang have not voiced their claim for a caste status per se, the trend of Hinduization is distinctly discernible. Like a caste-based occupational monopoly and exclusiveness, basket making has been adopted and internalized by this section of the Juang to give credence to the process of cultural mobility. In another tribal group, the Bada Gadaba, inhabiting Koraput district of Odisha, the institutionalized idol worship of the Hindu Gods and Goddesses, such as Lakshmi, Radha Krishna, and the sacred plant Tulsi (Ocimum sanctum), observance of Hindu festivals as per the Hindu calendar with usual pomp, etc. give credence to the ongoing process of Hinduization among the tribes of Odisha.

Similar process of Hinduization among many other tribal communities of Odisha can also be evinced in relatively modern times and their claim to have achieved the status of a farming caste for precisely the reason mentioned earlier. Example may be cited of the Rajkuli Bhuyian of Keonjhar, who have solely taken up wet cultivation as their primary occupation and are converted to the caste of cultivators with the use of typical surnames of the caste (Behura, 1983). Even the Bhuyian of more remote and less accessible Bonai of Sundergarh have 
become converted to the caste of warriors or the Khandayat, when some of them acquired landed property in course of time (Mahapatra, 1976). While the Desia Kondh of Phulbani, Suddha Saora of the Ganjam Agency and Koraput, and Sadhu Hor Santal of Mayurbhanj are on the verge of being converted to the caste of a cultivator because of their practice of wetland farming, the Raj Gond, Mirdha and other such communities of Sambalpur and Sundergarh have started tracing their origin from the local chieftains and claiming their Kshtriya ancestry. The process of parochialization and eventual infiltration of the Hindu cultural ideologies and practices have made them Hindus for all practical purposes. Hindu barbers, washermen, and other service castes have started serving them. This process warrants probing into the possibility of ethnic and cultural admixture among some of the dominant agricultural castes in India, like the Mudaliar of Tamil Nadu, Kunbi of Madhya Pradesh, Reddy of Andhra Pradesh, Okkaliga of Karnataka, and Khandayat of Odisha.

Also,the adoption of craft specialization is not uncommon in tribal Odisha. Besides the acceptance of basket making by the Juang (Bose, 1967), there are instances of Bathudi barbers, washermen and potters in Mayurbhanj, who were recognized by the Raja of Mayurbhanj and were conferred the caste status, are now undergoing the process of Sanskritization for an upward caste mobility in the local social hierarchy (Behura 1978). The other trend in the mechanism of bi-directional flow of culture traits is just the reverse process of what has been delineated above. The internalization of typical tribal characters by the encysted caste communities and the operationalization of the processes of universalization and tribalization are also not uncommon in Odisha. Behura observes that among the Koya, Kondh and Gadaba of south Odisha, three artisan castes have become assimilated to such an extent that except the retention of caste endogamy, they can be easily identified with their encysting tribes. These three artisan castes of blacksmiths, potters and weavers have settled down among these tribes for 
generations and have been serving them for pecuniary advantages throughout their span of habitation (Behura, 1983).

The process of universalization, besides the case of Savara deity Jagannath, has been observed among the Hill Bhuyian of Sundergarh, where a tribal deity, Kanta Kuanri, had been given the status of a state deity by the Raja of Bonai and was later identified as Durga. A similar example is often cited that the Goddess Samalai of Sambalpur was claimed to be worshipped by the local Sahara community and was eventually adopted as the state deity by the king of Sambalpur (Mahapatra, 1976).

This bi-directional flow of culture between the tribes and castes of Odisha can be, under no circumstances, be reduced only to the process of Hinduization, as there has been a tendency towards total assimilation. There was emulation of the typical form of social organization, economic pursuits, language or dialect, along with the ideological system of the neighbours (Behura, 1983). The encysted castes have even adopted tribal dialects and tribal way of life, to the extent of participating in community festivals with them, quite often headed by a tribal priest. It is, therefore, plausible to assume that despite many strong claims of tribes and castes of Odisha belonging to two separate cultural genres, in reality the boundary has been much more fluid and porous facilitating tribe-caste continuum on a long-term basis, each one of them contributing to what we see today as the Odia culture.

\section{Tribes in transition}

Culture and society are dynamic. Culture and society change over time due to several factors - exposure, invention, experimentation and change in surrounding environment. The tribal societies are also no exception. When we observe the social status and cultural components of tribal societies we find that in our country the tribal societies are in different stages of transition. They are in different stages of picking up or imbibing components of modern world like education, economic activities, dress and recreation, food habit, health 
seeking behaviour and world view etc. There is lack of uniformity in these domains among the different tribes in different regions of the country. This specific character of the tribal groups bears the importance in that while making policies for social and economic development one has to be aware of such levels of transition. For example, we have come across highly educated tribal groups in north eastern states like Mizoram whereas, areas like Odisha and Bihar the tribal people are very less educated. The situation is same for many other social indicators of development among tribal groups across the country. Thus, tribal policies must be group specific or region specific. Flatly generalized uniform policies may not serve the purpose.

\section{Conclusion}

By traditional definition, tribal societies are self-sufficient. Selfsufficiency means they need not to interact with non-tribal societies for their social, cultural and physical existence. This very nature of tribal people kept themselves away from the rest of the other societies. The tribal people had crude form of trade relations with non-tribal world, but that was not sufficient to penetrate their social core. Thus, it is quite clear that exclusion of tribal societies was a self-imposed criterion. Contrary to this fact, the caste societies were the integral part of Hindu caste system.

The Scheduled Castes, generally the lowest in the social rank, have socio-cultural and economic dependency on other caste groups. Thus exclusion of such societies is due to its social customs, work attachment and legendry mandates by social authorities present among the greater Hindu society. The perceived and manifested exclusions are mostly due to the fact that the other part of the society thinks them not suitable to be in the same line of interaction. From these two explanations one can draw the difference of exclusion: Tribal groups are excluded groups because they are not a part of the greater traditional Hindu society. At best they may be termed as the 
parallel segments in a different domain. Scheduled Castes, on the contrary, a part and parcel of the greater Hindu society, are excluded as neglected parts thereof. Therefore, it is opined that in the process of nation building process, while the Scheduled Castes need uplifting in social status, the tribal societies need a meaningful integration and positive inclusion.

Culture is a dynamic entity. There is constant change and also relative stability to maintain equilibrium. It accepts new components-invented, derived or borrowed, adapt to its own niche and merges it to enrich its totality. Thus, exposure to nontribal domain at different period of ethnic history has earmarked numerous changes in tribal cultural component. The extent and intensity of such changes primarily depend on a society's need based integrity to its cultural components and life ways. A two way change- say for example, the exposure to new culture and change in surrounding environment, physical, social and economic, speeds up the change process in cultural domain of a tribal group.

In a negative inclusion process these two forces are rampant and, therefore, cultural disintegration is rapid. This is a negative trend among the tribal groups, who in turn are in the verge of losing its unique identity and problems of identity crisis occur. One has to be clear about the fact that no one can deny changes in society. But penetration by an alien culture that does not have basic linkage to the core of people's life ways in not a welcome change at all. Social scientists have mentioned that social and cultural disintegration through such forces has made tribal people more vulnerable to severe exploitation throughout the country.

In Indian society tribe and caste are not exclusive and clear-cut social universes. They no doubt constitute separate social domains that are in socio-economic interaction since millennia. In social science parlance 'tribe' and 'caste' are understood as distinct social types for analytical purposes. There is no difference of opinion with regard to the fact that tribal culture 
constitutes a dimension of the 'Little Tradition' of the Indian civilization with its rich cultural heritage and has contributed to the shaping up of this great Indian civilization. Tribe and caste not only mutually influence each other, but together they interact with the 'Great Tradition' of India. Despite the British policy of tribal isolation in India and deliberate division of Indian social universe into that of the tribes and castes, tribes share Indian civilization in its broadest spectrum, in spite of varying degrees of their agglomeration, economy and variation in speech. Therefore, caste system, which is usually conceptualized as immutable and monolithic, is a misnomer, which is evidenced from the empirical evidences of bidirectional cultural flow between the tribes and castes of Odisha. Because of their contribution to the composite culture and religion of Odisha, tribal cultures ought to occupy same space in the contemporary discourse on Odia culture, language and history as do the castes of Odisha.

\section{References}

Atkinson Rob, and Divoudi, Simin (2000). The concept of social exclusion in the European Union: Context, development and possibilities. Journal of Common Market Studies, 38(3), 427-448.

Basu, A.R., and Nijhawan, S. (1994. Tribal development administration in India 1994. New Delhi: Mittal Publications.

Behura, N.K. (1978) Peasant potters of Odisha. New Delhi: Sterling.

Behura, N. K. (1983) Structural Continuity of Tribal Culture and Indian Civilization: An Analysis of Odishan Situation, Journal of Social Research, 26 (2), 1-25.

Behura, N. K., and Panigrahi, N. (2005). Development of primitive tribal groups (ptg) and the role of government in Odisha. In Sarita K. Chaudhari. and Sucheta Sen Chaudhari (eds.), Primitive tribes in contemporary 
India: Concept, ethnography and demography (Vol. 2) (pp. 227-258). New Delhi: Mittal Publications.

Bhalla, A.,and Lapeyre, F. (1997). Social exclusion: Towards an analytical and operational framework. Development and Change, 28, 413-433.

Benn, M. (2000). New labour and social exclusion. Political Quarterly, 71 (3), 309-318.

Bose, N.K. (1967) Culture and society in India, Bombay: Asia Publishing Co.

Burchardt, T., Grand, J., and Piachaud, D. (1999). Social exclusion in Britain 1991-1995. Social Policy and Administration, 33 (3), 227-244.

Das, T.P. (2005) Enigma of 'Daru Brahma'. In Utkalika (pp. 35-38). Hyderabad: Kalinga CulturalTrust.

Dash, P. (2005). Jagannath culture. In Utkalika (pp.10-19). Hyderabad: Kalinga CulturalTrust.

Deogaonkar, S. G. (1994). Tribal administration and development: With ethnographic profiles of selected tribes. New Delhi: Concept Publishing Company.

Figueredo (Eds.): Social exclusion: Rhetoric, reality and responses. Geneva: International Labour Organization.

Fried, M. (1966) The evolution of political society. New York: Random House.

George, J., and S. S. Sree Kumar. (1994). Tribal development: Legislation and enforcement. New Delhi: Commonwealth Publishers.

Kalia, S.L. (1959). Sankritization and tribalization. Bulletin of Tribal Research Institute, Chindwara (M.P.), 2(4),3343.

Leach, E.R. (1964) Political system of highland Burma. London: Bell and Sons.

Luhman Niklas 1990. Political theory in the welfare state. Berlin, New York: Walter de Gruyter.

Mahapatra, L.K. (1976). Gods, kings and the caste system in India, In A. Bharati (ed.), The realm of the extrahuman: Agents and audiences (pp. 51-72): The Hague: Mouton. 
Marriott, McKim (ed.) (1961). Village India. Bombay: Asia Publishing House.

Misra, K.K. (1986). From millenarianism to Jharkhand: The changing nature of social movements in tribal Chotanagpur. Journal of Asian and African Studies, Leiden, XXI (3-4), 226-236.

Misra, K.K. (1995). Tribalism and national integration. In A.K.Singh and M.K.Jabbi (eds), Tribals in India (pp.159-173). New Delhi: Har Anand Publications.

Misra, K.K. (2003). Inter-jati exchange relations in village India: Some reflections. Journal of the Indian Anthropological Society, 38 (1), 1-8.

Misra, K.K. (2005). Evolution and devolution of Devadasi system in India: A socio-historical analysis (with K.Koteswar Rao), Journal of Indian Anthropological Society, 40 (1), 31-49.

Ray, N. (1972). Introductory address. In K.S.Singh (ed.) Tribal situation in India, 3-24. Simla: Institute of Advanced Studies.

Redfield, R. (1953). The primitive world and its transformations. Ithaca: Great Seal Books.

Redfield, R. (1956). Peasant society and culture: An anthropological approach to civilization. Chicago University Press.

Satyanarayana, M. (1990). Tribal development in India: A trend report. New Delhi: Inter-India Publications.

Singer, M. (ed.) (1959). Traditional India: Structure and change. Philadelphia: American Folklore Society.

Singh, Y. (1980). Social stratification and change in India, Delhi:

Sinha, M., and Surajit, C. (1958). Tribal cultures of peninsular India as a dimension of little tradition in the study of Indian civilization: A preliminary statement. Journal of American Folklore, 71 (28).

Sinha, S. C. (1962) State formation and Rajput myth in tribal Central India, Man In India, XLII (1). 
Sinha, S. C. (1981) Tribes and Indian civilization: Transformation process in modern India, Man in India, 61(2).

Stebbing E. P. 1983. The Forests of India,. Volume I to IV. Reprinted, London: Periodical Expert Book Agency

Verma, R. C. (2002). Indian tribes through the ages. New Delhi: Publication Division, Ministry of Information and Broadcasting, Government of India.

Vidyarthi, L.P. (1978). Rise of anthropology in India (Vol. II). New Delhi: Concept Publishing.

The author is a Reader in Department of Sociology, Ravenshaw University, Cuttack. 